\title{
Investigation of planktonic foraminifera with ToF-SIMS
}

\author{
C. Crone,${ }^{1}$ G. Vering, ${ }^{1}$ B. Hönisch, ${ }^{2}$ J. Bijma ${ }^{2}$ and H. F. Arlinghaus ${ }^{1 *}$ \\ ${ }^{1}$ Physikalisches Institut der Universität Münster, D-48149 Münster, Germany \\ ${ }^{2}$ Carbon Group, Alfred Wegener Institute for Polar and Marine Research, D-27570 Bremerhaven, Germany
}

Received 16 July 2001; Revised 30 November 2001; Accepted 24 December 2001

\begin{abstract}
Various oceanic sediment properties deliver useful information for reconstructing environmental parameters of the past. Those properties that are closely related to environmental parameters are called 'proxies'. They are measurable descriptors for desired (but unobservable) variables. Among others, promising advances were made in the field of boron isotopes in foraminiferal shells as a palaeo-pH recorder. The isotope ratios are typically measured with thermal ionization mass spectrometry, which requires $\sim 200$ shells to achieve high accuracy. We have investigated the possibility of using time-of-flight secondary ion mass spectrometry (ToF-SIMS) for imaging single foraminiferal shells and determining their elemental and isotopic distribution. The data show that ToF-SIMS is a useful technique for determining their elemental distribution and for measuring boron isotopic ratios with high precision in a single foraminiferal shell. The use of well-characterized standards for calibration as well as appropriate surface cleaning procedures for foraminiferal shells should improve data accuracy. Furthermore, the data imply that the parallel detection of all masses would simplify the establishment of new proxies. Copyright $(C)$ 2002 John Wiley \& Sons, Ltd.
\end{abstract}

KEYWORDS: foraminifera; ToF-SIMS; mass spectrometry; isotope ratio; boron; proxie; environment

\section{INTRODUCTION}

One of the most important scientific challenges today is to understand and quantify the interaction between the atmospheric $\mathrm{CO}_{2}$ budget and the oceanic carbon cycle. The values of at least two components are required to calculate the oceanic carbonate chemistry, and this can be any combination of total dissolved inorganic carbon, alkalinity, $\mathrm{pH}$ or related ion concentrations. To estimate variations in the past oceanic carbon cycle, the desired components cannot be observed directly and thus need to be derived from properties that are closely related to the parameter in question. Among others, promising advances were made in the field of boron isotopes in foraminiferal shells as a palaeo- $\mathrm{pH}$ recorder. ${ }^{1-3}$

Foraminifera are unicellular organisms that occur all over the world ocean. They live either in the water column (planktonic species) or on the seafloor (benthic species). During their life-cycle, foraminifera precipitate a calcitic shell. Empty shells accumulate in the sediments on the seafloor, where they build an important ocean archive. The trace metal and isotopic composition of foraminiferal shells record seawater chemistry and, as such, allow the reconstruction of ocean and climate variability on geological time-scales. ${ }^{4-6}$

The measurable descriptors for desired but unobservable environmental variables, e.g. temperature, salinity, carbon dioxide concentration, etc., are called 'proxies'. Established

*Correspondence to: H. F. Arlinghaus, Physikalisches Institut der Universität Münster, D-48149 Münster, Germany.

E-mail: arlinghaus@uni-muenster.de foraminiferal proxies are the stable isotopic compositions of $\delta^{11} \mathrm{~B}, \delta^{13} \mathrm{C}$ and $\delta^{18} \mathrm{O}$, and trace metal/Ca ratios such as $\mathrm{Sr} / \mathrm{Ca}$ and $\mathrm{Mg} / \mathrm{Ca}$. Further investigation of elemental and isotopic distributions covering a wide spectrum of elements, e.g. Ba, $\mathrm{Zn}, \mathrm{Mn}, \mathrm{Co}, \mathrm{Ni}$, As or rare-earth elements, may lead to the evaluation of new proxies.

Typically, thermal ionization mass spectrometry (TIMS) is used to determine boron isotopic ratios from foraminiferal shells. ${ }^{7}$ Approximately 200 foraminiferal shells are necessary to achieve high accuracy in the measurements of isotopic ratios. Furthermore, TIMS instruments such as magnetic mass spectrometers allow the simultaneous analysis of only a few isotopes. Thus, a technique that is able to take simultaneous isotopic measurements of all elements on a smaller number of foraminiferal shells could significantly improve palaeoclimatic research. It would also allow the number of foraminiferal shells in culture experiments to be reduced and thus enhance the ability to investigate the influence of environmental parameters as well as intra- and interspeciesspecific variability. Owing to the low specific abundances of benthic foraminifera, no single-species benthic boron isotope record exists to date. In the sense of investigating the role of the deep sea in the past global carbon cycle, it is of major scientific importance to extend the existing mixed foraminifera benthic records to single-species records. ${ }^{2,3} \mathrm{We}$ have investigated the possibility of using time-of-flight secondary ion mass spectrometry (ToF-SIMS) for imaging single foraminiferal shells and determining their elemental and isotopic distribution with high precision. 


\section{EXPERIMENTAL}

Secondary ion mass spectrometry utilizes a technique in which the sample is bombarded with a focused, energetic ion beam that sputters particles off the sample surface. A fraction of the sputtered particles is ejected as ions. These ions are extracted, mass analysed and detected. With a time-of-flight mass spectrometer, all masses can be detected simultaneously on each primary ion pulse. Charge compensation for insulator analysis is possible using pulsed low-energy electrons, which are introduced during the time interval between ion pulses. With a liquid-metal ion gun, high-resolution images with a lateral resolution up to $50 \mathrm{~nm}$ in diameter can be obtained by scanning the ion beam over the sample (up to an area of $500 \mu \mathrm{m} \times 500 \mu \mathrm{m}$ ). The combination of two-dimensional imaging with depth profile capabilities allows the visualization of the three-dimensional distribution of elements.

The SIMS instrument is equipped with a reflectrontype time-of-flight analyser, an electron impact ion source (primary ion energy $11 \mathrm{keV}$, different positively charged noble gases) used for the determination of elemental composition, a liquid-metal ion gun $\left(25 \mathrm{keV}, \mathrm{Ga}^{+}\right)$for imaging applications and a dual-beam ion gun (1-10 keV, noble gases, $\mathrm{O}_{2}{ }^{+}, \mathrm{Cs}^{+}$) for presputtering experiments or depth profiling.

\section{PREPARATION}

To determine the lateral differences of elemental concentration ratios, either the intact or the broken shell is attached to a silicon substrate via carbon-based conducting adhesives. It is thus possible to obtain high-resolution ion images of the inner and outer part as well as from the edge of a foraminiferal shell. To investigate the boron isotope ratios, single foraminifers were dissolved in $1 \mu \mathrm{l}$ of $2 \mathrm{~N}$ quartzdistilled $\mathrm{HCl}$. The dissolved foraminifera, as well as liquid seawater standards, were pipetted onto Au-coated Si wafer surfaces and then air dried.

\section{RESULTS AND DISCUSSION}

\section{Lateral elemental distribution}

Figure 1 shows a photomicrograph of a living planktonic foraminifer Orbulina universa. About 3000-7000 dinoflagellate symbionts are distributed in a halo around the calcitic sphere. Numerous large pores penetrate the shell.

Figure 2(a) depicts the lateral distribution of the elements ${ }^{24} \mathrm{Mg}$ and ${ }^{28} \mathrm{Si}$ and of the two calcium isotopes ${ }^{40} \mathrm{Ca}$ and ${ }^{44} \mathrm{Ca}$ obtained from the outer part of a foraminiferal shell using a liquid-metal ion gun and a scanning area of $500 \mu \mathrm{m} \times 500 \mu \mathrm{m}$. The Ca isotope ratios were measured to investigate variations in the lateral isotopic distribution. The number below the images displays the total number of counts of this element during the acquisition. The analysed samples were picked from a core top collected during R. V. Meteor Cruise 10 in the BIOTRANS area $\left(47^{\circ} \mathrm{N}, 20^{\circ} \mathrm{W}\right)$. For $\mathrm{Ca}$ and $\mathrm{Mg}$ a homogeneous distribution can be observed, whereas the $\mathrm{Si}$ distribution depicts localized spots of higher concentration. The lateral distributions of the two calcium isotopes do not

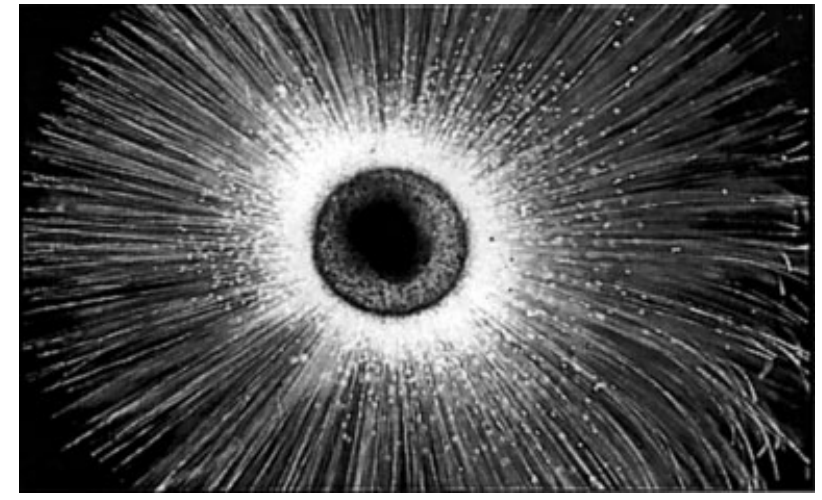

Figure 1. Photomicrograph of a foraminifer (Orbulina universa) with spines and dinoflagellate symbionts. Field of view $=5 \mathrm{~mm} \times 3 \mathrm{~mm}$.

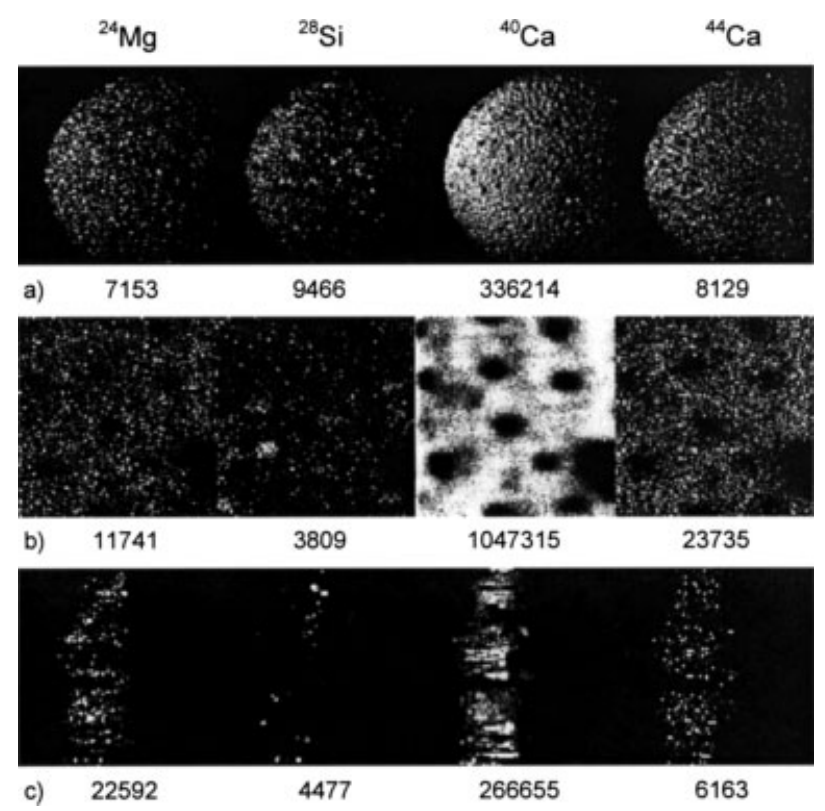

Figure 2. The ToF-SIMS images of the outer (a), inner (b) and edge (c) of a foraminiferal shell. Scanning areas: (a) $500 \mu \mathrm{m} \times$ $500 \mu \mathrm{m}$; (b) $50 \mu \mathrm{m} \times 50 \mu \mathrm{m}$; (c) $100 \mu \mathrm{m} \times 100 \mu \mathrm{m}$.

show a significant difference. All images show a decrease of intensity from the left to the right part of the shell. This is caused by the primary ion beam coming from the left side, which results in a typical shadow effect due to the round topography. Similar images also were obtained for a variety of other elements, such as $\mathrm{Na}, \mathrm{Zn}$, As and Sr.

Figure 2(b) shows images of the same elements from the inner part of the shell with a scanning area of $50 \mu \mathrm{m} \times 50 \mu \mathrm{m}$. The pores are especially visible in the $\mathrm{Ca}$ image. From this image, the size of the pores could be determined to be $5-15 \mu \mathrm{m}$ in diameter. The observed Si signal is lower compared with the outer part of the shell, whereas the $\mathrm{Mg}$ signal increases. High-concentration Si spots also can be observed on the inner surface.

Figure 2(c) shows the distribution of the same elements obtained from the edge of a foraminiferal shell using a field of view of $100 \mu \mathrm{m} \times 100 \mu \mathrm{m}$. The outer side is on the right side and the inner part on the left side of the image. The Ca image shows the formerly visible pores as tunnels from the outer 
to the inner part of the shell. There is a noticeable difference between the elemental distribution of $\mathrm{Si}$ and $\mathrm{Mg}$. Magnesium shows a homogeneous distribution over the entire side of the shell, whereas Si depicts some high-concentration spots mainly at the outer surface. Additional images with higher magnification also could be obtained; however, for images with very high magnification (field of view $<25 \mu \mathrm{m} \times 25 \mu \mathrm{m}$ ), the lateral resolution decreases due to charging effects.

The images clearly show that the compositional differences between the inner and the outer part of the foraminiferal shell can be detected readily with ToF-SIMS. Furthermore, the same technique can be used to measure directly the isotopic ratios in the inner or outer parts of the shell. Cleaning the surface with ion sputtering might significantly reduce interferences due to adhering surface contamination.

\section{The ${ }^{11} \mathrm{~B} /{ }^{10} \mathrm{~B}$ ratio of foraminifera dissolved in $\mathrm{HCl}$}

The dominant aqueous species of boron in seawater are $\mathrm{B}(\mathrm{OH})_{3}$ and $\mathrm{B}(\mathrm{OH})_{4}{ }^{-}$. The relative proportions of the two boron species are $\mathrm{pH}$ dependent. At $\mathrm{pH} \leq 6 \mathrm{~B}(\mathrm{OH})_{3}$ dominates, whereas at $\mathrm{pH} \geq 11$ most boron exists in the form of $\mathrm{B}(\mathrm{OH})_{4}{ }^{-}$. The two stable isotopes ${ }^{11} \mathrm{~B}$ and ${ }^{10} \mathrm{~B}$ make up close to $80 \%$ and $20 \%$ of the total boron, respectively. The lighter isotope ${ }^{10} \mathrm{~B}$ is enriched in the charged species $\mathrm{B}(\mathrm{OH})_{4}{ }^{-}$. It is also the isotopically lighter $\mathrm{B}(\mathrm{OH})_{4}{ }^{-}$that is incorporated into carbonate structures. The $\mathrm{pH}$-dependent isotopic fractionation between $\mathrm{B}(\mathrm{OH})_{3}$ and $\mathrm{B}(\mathrm{OH})_{4}{ }^{-}$leads to a characteristic slope of these species vs. $\mathrm{pH}$. Because the steepest slope in the $\mathrm{B}(\mathrm{OH})_{4}{ }^{-}$vs. $\mathrm{pH}$ curve is in the typical $\mathrm{pH}$ range of seawater ( $\mathrm{pH} 7.8-8.3$ ), a slight fluctuation in $\mathrm{pH}$ at the site of calcification can change the abundance of $\mathrm{B}(\mathrm{OH})_{4}{ }^{-}$ and thereby change the isotopic signature significantly..$^{8,9}$ The isotopic signature of $\mathrm{B}(\mathrm{OH})_{4}{ }^{-}$in carbonates is given in the $\delta$-notation: $\delta^{11} \mathrm{~B}(\% \mathrm{o})=\left(R_{\mathrm{s}} / R_{\mathrm{std}}-1\right) \times 1000$, where $R_{\mathrm{s}}={ }^{11} \mathrm{~B} /{ }^{10} \mathrm{~B}$ is the ratio of the sample and $R_{\text {std }}={ }^{11} \mathrm{~B} /{ }^{10} \mathrm{~B}$ is the ratio of a seawater standard (IAPSO). ${ }^{10}$

For the first time, ToF-SIMS measurements were used here to determine $R_{\mathrm{s}}$ in different foraminifera and $R_{\text {std }}$ in the IAPSO seawater standard. For these experiments, we used samples from multicore GeoB 3603-1 and gravity core GeoB 3603-2, both collected by R. V. Meteor in January 1996 at a water depth of $2840 \mathrm{~m}$. At this locality $\left(35^{\circ} 07\right.$, $\left.5^{\prime} \mathrm{S}, 17^{\circ} 32,6^{\prime} \mathrm{E}\right)$, the sediments are dominated by carbonate ooze. Shells of Orbulina universa were hand-picked from the surface sediments $(0-1 \mathrm{~cm})$ of multicore GeoB 3603-1 and from $38 \mathrm{~cm}$ sediment depth of gravity core GeoB 3603-2. The deeper samples are estimated to belong to the Last Glacial Maximum (LGM).
Initial experiments were conducted with a pulsed $11 \mathrm{keV}$ primary $\mathrm{Ar}$ ion beam. It was observed that the boron isotope ratio slightly changes with increasing analysis time. This might be caused by an enrichment of ${ }^{10} \mathrm{~B}$ at the surface of the dried dissolved foraminiferal shell. However, cleaning the surface by presputtering it with a $1 \mathrm{keV}$ Xe d.c. ion beam almost eliminated this effect (presputtering area $500 \mu \mathrm{m} \times 500 \mu \mathrm{m}$; analysis conditions for foraminifera: time $=1800 \mathrm{~s}$, primary ion dose density $(P I D D)=6.3 \times 10^{16} \mathrm{~cm}^{-1}$; analysis conditions for IAPSO: time $=1230 \mathrm{~s}$, PIDD $=4.3 \times 10^{16} \mathrm{~cm}^{-1}$ ).

Figure 3 shows the boron isotope ratios of Holocene foraminifera (GeoB 3603-1). Forty-one consecutive measurements were taken, with a repetition rate of $5 \mathrm{kHz}$ and a total analysis time of $1800 \mathrm{~s}$ for each spot. Glacial foraminifera (GeoB 3603-2) as well as the IAPSO seawater standard were analysed under the same conditions (always with presputtering). Despite presputtering, a small increase in the ${ }^{11} \mathrm{~B} /{ }^{10} \mathrm{~B}$ ratio still can be observed. Whether the increase is caused by sample preparation, preferential sputtering or other effects has to be investigated in more detail in future experiments.

A summary of the preliminary data is presented in Table 1 . The results show that the precision of the water standard analysis is much higher than that of the foraminiferal results. This can be explained by the differences in the yields obtained. The boron yield of the seawater standard is $\sim 100$ times higher than the yield of the dissolved foraminifera. A statistical analysis shows that the deviation is limited by the statistical abundance, implying that longer analysis times will improve accuracy.

Studying the boron isotopic composition of planktonic foraminifera, Sanyal et al. estimated that the $\mathrm{pH}$ of the surface waters of the Atlantic and Pacific oceans was

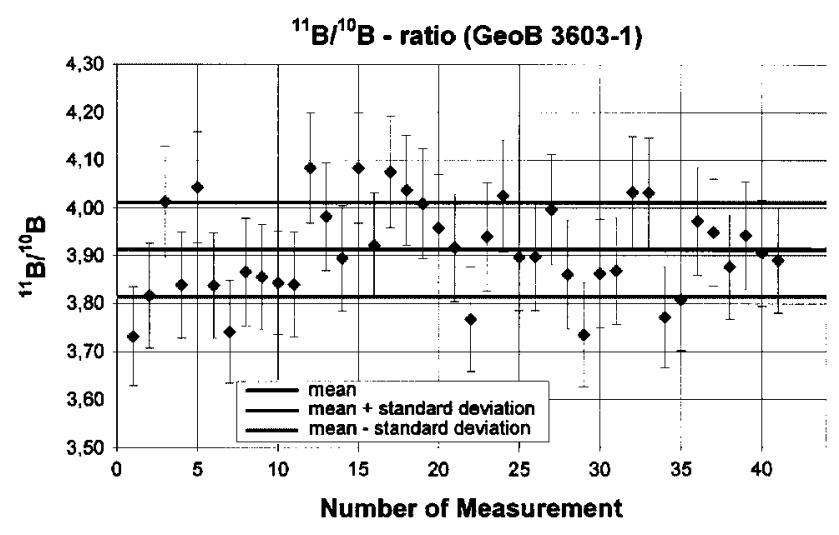

Figure 3. The ${ }^{11} \mathrm{~B} /{ }^{10} \mathrm{~B}$ ratios for Holocene Orbulina universa (GeoB 3603-1): 41 consecutive measurements.

Table 1. The ${ }^{11} \mathrm{~B} /{ }^{10} \mathrm{~B}$ ratios for Holocene Orbulina universa (GeoB 3603-1), glacial Orbulina universa (GeoB 3603-2) and IAPSO seawater standard

\begin{tabular}{lcccccc}
\hline Sample & $\begin{array}{c}\text { Analysis } \\
\text { cycles }\end{array}$ & $\begin{array}{c}\text { Total analysis } \\
\text { time }(\mathrm{min})\end{array}$ & $\begin{array}{c}\text { Primary ion dose } \\
\text { density }\left(10^{15} \mathrm{~cm}^{-1}\right)\end{array}$ & Sample mean & $\begin{array}{c}\text { Standard } \\
\text { deviation }\end{array}$ & $\begin{array}{c}\text { Standard error } \\
\text { of the mean }\end{array}$ \\
\hline GeoB 3603-1 & 41 & 1230 & 1.4 & 3.913 & 0.099 & 0.015 \\
GeoB 3603-2 & 43 & 1290 & 1.5 & 3.815 & 0.094 & 0.014 \\
IAPSO & 34 & 1020 & 1.1 & 4.039 & 0.028 & 0.005 \\
\hline
\end{tabular}


higher by $0.2 \pm 0.1$ units during the last glaciation. ${ }^{1}$ This $\mathrm{pH}$ increase is equal to an increase of $0.007 \pm 0.004$ in the ${ }^{11} \mathrm{~B} /{ }^{10} \mathrm{~B}$ ratio, which is much smaller than the difference of 0.1 determined by the ToF-SIMS measurements. Even considering coastal influences or changes in the general circulation patterns at the core site will not let differences on such a scale appear reasonable. A difference of \pm 0.004 in the ${ }^{11} \mathrm{~B} /{ }^{10} \mathrm{~B}$ ratio is equal to a $\mathrm{pH}$ difference of \pm 0.1 units. The differences were very likely caused by surface contamination. This artefact can be minimized by more elaborate cleaning procedures (e.g. bleaching). However, the experiments show promising possibilities of using ToF-SIMS for analysing single foraminiferal shells.

\section{CONCLUSION AND OUTLOOK}

The data show that ToF-SIMS might be a powerful tool for obtaining information about elemental distributions and isotopic ratios in foraminiferal shells. In particular, the parallel detection of all masses in positive or negative spectra could be very helpful for finding new proxies. Using well-characterized standards for calibration could improve data accuracy. To reduce surface contamination, special intensive cleaning methods have to be investigated. In addition, new ways of preparation could lead to better results. It should, for instance, be possible to embed the entire foraminiferal shell into conducting artificial resin and then cut out slices for ToF-SIMS analysis with a microtome. The technique also would allow the study of intra- and interspecific variabilities, especially in benthic foraminifera. Using more sensitive and efficient techniques such as resonance post-ionization, ${ }^{11}$ which allows neutrals sputtered from the surface to be detected selectively, could improve the precision and accuracy in future experiments to a great extent.

\section{REFERENCES}

1. Sanyal A, Hemming NG, Broecker WS. Global Biogeochem. Cycles 1997; 11: 125.

2. Sanyal A, Hemming NG, Broecker WS, Lea DW, Spero HJ, Hanson GN. Paleoceanography 1996; 11: 513.

3. Sanyal A, Hemming NG, Hanson GN, Broecker WS. Nature 1995; 373: 234.

4. Wefer G, Berger WH, Bijma J, Fischer G. In Use of Proxies in Paleoceanography: Examples from the South Atlantic, Fischer G, Wefer G (eds). Springer-Verlag: Berlin, 1999; 1-68.

5. Lea DW. In Reconstructing Ocean History: a Window into the Future, Abrantes F, Mix AC (eds). Kluwer Academic/Plenum Press: London, 1999; 321-327.

6. Lea DW. In Modern Foraminifera, Sen Guppta BK (ed.). Kluwer Academic: London, 1999; 259-277.

7. Hemming NG, Hanson GN. Chem. Geol. 1994; 114: 147.

8. Hemming NG, Hanson GN. Geochim. Cosmochim. Acta 1992; 56 : 537.

9. Hemming NG, Reeder RJ, Hanson GN. Geochim. Cosmochim. Acta 1995; 59: 371.

10. Burton JD. In Oceanography: an Illustrated Guide, Summerhayes CP, Thorpe SA (eds). Manson: London, 1996; 165-181.

11. Arlinghaus HF, Spaar MT, Thonnard N, McMahon AW, Tanigaki T, Shichi H, Holloway PH. J. Vac. Sci. Technol. 1993; A11: 2317. 